\title{
Beyond Behavior: Prevalences, Penalties, and Ethno-racial Inequalities in Poverty
}

\author{
D. Adam Nicholson \\ Indiana University
}

April 8, 2021

\begin{abstract}
Ethno-racial differences in poverty are substantial and persistent in the US. To explain these differences, scholars have relied largely on behavioral explanations, which argue that poverty is the result of high prevalences of problematic behaviors or "risks." Given substantial differences in the prevalence of risks, scholars intuit that ethno-racial differences in poverty are explained by disproportionately high prevalences of risks in Black and Latino populations. However, these approaches rely heavily on untested assumptions regarding the relationship between risks and poverty rates. Using the 1993-2016 Current Population Survey and the Urban Institute's TRIM3 model to derive high-quality estimates of income and poverty, I confirm persistent and substantial ethno-racial differences in poverty. Next, I employ a prevalences and penalties framework to compare risks in Black, Latino, and white-lead households. This framework is then leveraged to estimate counterfactual models to predict Black and Latino poverty rates given alternative prevalences of risks. The findings demonstrate that if the prevalence of risks for Black and Latino Americans was equal that of whites, poverty rates would remain over twice as high for Black and Latino individuals compared to whites. Furthermore, even when risks are eliminated for Black and Latino Americans, poverty remains substantially higher compared to whites. These findings undermine behavioral approaches to understanding poverty and point to the need for scholars to pursue alternatives, including structural and political explanations.
\end{abstract}


One of the most important issues faced by scholars of inequality is the persistence of ethnoracial disparities. Ethno-racial differences in poverty have been widely studied by social scientists (Lin and Harris 2008; Ludwig-Dehm and Iceland 2017; O’Connell 2012; Patterson 2019; Thiede and Brooks 2018) and remain a salient issue in the United States (Council of Economic Advisers 2014; Lin and Harris 2008; Thiede, Kim, and Slack 2017). According to the official poverty measure (OPM), Black and Latino Americans are over twice as likely as whites to be poor (Semega et al. 2020).

The prevailing understanding of these disparities is based largely on approaches that center individual-level behaviors_ or risks, defined as "the individual labor market and family characteristics that are more common among the poor than the nonpoor" (Brady, Finnigan, and Hübgen 2017) — to explain poverty. According to these approaches, behaviors that increase the risk of poverty are the key mechanism in understanding the causes of poverty (AEI-Brookings 2015; Brady 2019; Sawhill 2003). Thus, since poverty is the result of undesirable behaviors (Bertrand, Mullainathan, and Shafir 2004; Durlauf 2011), ethno-racial disparities in poverty are the result of disproportionate problematic behaviors by those in minoritized groups (see Brady 2019).

Consistent with behavioralist approaches, risks, such as single motherhood, low education, young-headship, and unemployment, are significantly associated with poverty in many cases (Brady et al. 2017; Kohler et al. 2012; Rainwater and Smeeding 2003). Single motherhood is frequently cited to explain racial differences in poverty, especially between Black and white Americans (Haskins 2009; Iceland 2013; O'connor 2009). Indeed, over half of Black children in the US lived with a single parent in 2014 (Parker, Horowitz, and Mahl 2016), resulting partly from higher birth rates outside of marriage (Ellwood and Jencks 2004; Martinez, Daniels, and Chandra 2012). Overall, behavioralists contend that poverty is high in these contexts due to high prevalences of risks (Cruz and Ahmed 2018; Kaida 2015; Ku et al. 2018; Milazzo and Van de Walle 2015). In order to reduce poverty and 
ethno-racial disparities, the prevalence of risks must be reduced (AEI-Brookings 2015; McLanahan 2009).

Despite this extensive body of work, the widespread assumption that reducing risks among minoritized populations can reduce ethno-racial differences in poverty remains largely untested. Based on behavioral theories of poverty, the prevalence of risks, such as single-motherhood, low education, young headship, and unemployment, should be higher in populations with higher poverty rates. Furthermore, reductions in any of the four risks should result in reductions in poverty. Ultimately, similar prevalences of risks should result in similar rates of poverty across populations. Using data from the 1993-2016 Annual Social and Economic Supplement of the Census Bureau's Current Population Survey (CPS-ASEC), this study applies state-of-the-art approaches to test the validity of the behavioral approach to poverty. First, using high quality income measures, I examine differences in poverty between individuals living in Black, Latino, and white-lead households (HHs). ${ }^{1}$ Second, I employ linear probability models along with a framework that examines the risks of poverty in terms of both prevalences (the increase in probability of poverty associated with a risk) and penalties (the increased probability of poverty associated with a risk) (Brady et al. 2017). I then leverage this framework to predict poverty rates using counterfactual prevalences and penalties for the four risks to assess the role that risks play in ethno-racial gaps in poverty.

\section{ETHNO-RACIAL INEQUALITIES IN POVERTY}

People of color experience poverty at substantially higher rates than whites in the United States. This phenomenon has been widely studied by social scientists going back more than one

\footnotetext{
${ }^{1}$ Individuals in Asian-lead households were included in primary analysis; however, in the context of this study, the differences between Asian and white-lead households are largely non-significant, so the results are not presented. Nevertheless, future work should include a rigorous examination of Asian American poverty in the United States.
}

Working draft_-Please do not cite or quote without author's permission 
hundred years (Lin and Harris 2008; Ludwig-Dehm and Iceland 2017; O’Connell 2012; Patterson 2019; Thiede and Brooks 2018). W.E.B. Du Bois spoke to these inequalities when he asserted the importance of "the problem of the color line;" that is, "the relation of the darker to the lighter races of men in Asia and Africa, in America and the islands of the sea" (1903/2008). Furthermore, government assessments and academic studies alike demonstrate that these inequalities are persistent in the U.S. based on the official poverty measure (OPM) (Council of Economic Advisers 2014; Lin and Harris 2008; Thiede et al. 2017). While there were substantial declines in Black and Latino poverty following the 1950s these declines happened primarily in the period between 1959 and 1979 (Council of Economic Advisers 2014; Iceland 2019). According to the OPM ethno-racial inequalities in poverty have remained mostly stable since 1979 (Iceland 2019). At present, Black and Latino people in the U.S. are significantly more likely than whites to be officially poor (Iceland 2019). Based on the OPM, Black Americans are more than twice as likely to be in poverty $(18.8 \%)$ compared to white Americans (9.1\%), while Latino Americans (15.7\%) are over one and a half times more likely than whites to be in poverty (Semega et al. 2020).

In examining these differences, prior scholarship has overwhelmingly relied on the OPM. The OPM has several important limitations, including the use of an absolute threshold and the exclusion of tax and transfer income (Rainwater and Smeeding 2003; Smeeding 2016). Scholars have long argued the OPM threshold is too low and its basis too arbitrary (Citro and Michael 1995). Inclusion of tax and transfer income is essential in measuring poverty because welfare transfers alleviate poverty for millions of Americans and can significantly improve the well-being of recipients, both in the short and long-term (Brady 2019; Fox et al. 2015; Rainwater and Smeeding 2003). Furthermore, exclusion from or lack of access to welfare transfers is a substantial source of inequality and can explain why some remain poor while others are lifted out of poverty (Brady et al. 2017). Studies which incorporate tax and transfer income still find persistent ethno-racial inequalities 
in poverty. For example, Baker et al. (2020) find that from 2013 to 2017, Black poverty was 10.113.9 percentage points higher than white poverty, and Latino poverty was 10.4-10.9 percentage points higher. Thus, even according to improved measures of poverty, Black and Latino Americans remain about twice as likely to be poor as whites.

\section{BEHAVIORAL EXPLAINATIONS OF POVERTY}

Previous studies have focused primarily on individual-level characteristics to explain differences in poverty. Also known as "behavioral" theories (Brady 2019), these approaches emphasize the role of risky and problematic behaviors (Haskins 2009; Iceland 2019; O'connor 2009). From a behavioral perspective, individual conduct is the key mechanism driving poverty (AEI-Brookings 2015; Gennetian and Shafir 2015; Sawhill 2003). Poverty is the result of undesirable behaviors or traits that increase the risk of being in poverty, such as single motherhood or unemployment (Bertrand et al. 2004; Durlauf 2011). Based on this framework, group differences in poverty arise from disparate prevalences of risk factors. In other words, "according to behavioralists, racial disparities in poverty result from a disproportionate amount of problematic behavior among racial minorities.” (Brady 2019:158).

Central to many behavioral approaches is the role of "culture" as an explanatory mechanism. Indeed, there has been a recent resurgence in scholarship that focus on the role of incentives and culture as the primary source of risky behavior (Bertrand et al. 2004; Durlauf 2011; Patterson and Fosse 2015). Culture explains counterproductive behaviors that cause poverty (Dahl, Kostøl, and Mogstad 2014) and constitute the "processes and mechanisms that lead to the reproduction of poverty" (Small, Harding, and Lamont 2010:23). These approaches question "whether the cultural models and motives that the poor internalize might have an 'exogenous explanatory power' that serves to inhibit socioeconomic success" (Vaisey 2010:96). For example, Vaisey (2010) contends that low educational aspirations of youths in poverty lead to both lower levels of education and

Working draft_-Please do not cite or quote without author's permission 
unemployment. Harding $(2007,2011)$ argues that a wide array of competing and conflicting cultural models in poor neighborhoods discourages educational attainment and encourages problematic sexual behaviors, resulting in a higher prevalence of single motherhood and young headship.

Consistent with behavioralist theories, risks, such as single motherhood, low education, young-headship, and unemployment, are significantly associated with poverty in many cases (Brady et al. 2017; Kohler et al. 2012; Rainwater and Smeeding 2003). Many scholars conclude that poverty can impose cognitive burdens and increase stress, which can result in low educational attainment (Hannum and Xie 2016; McEwen and McEwen 2017; McLoyd, Jocson, and Williams 2016). Behavioralist scholars argue that in response to poverty, a culture arises which discourages education, employment, and marriage and encourages welfare dependency and births outside marriage (Dahl et al. 2014; Harding 2010). Single motherhood is frequently cited to explain racial differences in poverty, especially between Black and white Americans (Haskins 2009; Iceland 2013; O'connor 2009). Indeed, over half of Black children in the US lived with a single parent in 2014 (Parker et al. 2016), partly resulting from higher rates of birth outside of marriage (Ellwood and Jencks 2004; Martinez et al. 2012). While marriage in the U.S. is declining overall, the decline is steeper in Black and Latino households, compared to whites (Raley, Sweeney, and Wondra 2015). Overall, behavioralists contend that poverty is high in these contexts due to high prevalences of risks and counter-productive behaviors (Cruz and Ahmed 2018; Kaida 2015; Ku et al. 2018; Milazzo and Van de Walle 2015). Thus they conclude that to reduce poverty the prevalence of risks must be reduced (AEI-Brookings 2015; McLanahan 2009).

However, the relationship between risks and poverty is largely misunderstood. While there are clear associations between risks and poverty, these relationships are not necessarily causal (Streib et al. 2016). For example, while single motherhood has been one of the most widely studied risks associated with poverty, Brady and colleagues (2017) find that in 19 of 29 rich democracies studied 
there is no significant association between single motherhood and poverty. Bloome (2017) shows that there is no disadvantage in upward mobility associated with single parenthood among children from low-income families. Examining the U.S., Baker (2015) demonstrates that while the association between poverty and employment has grown stronger since the 1970s, the association between poverty and marriage has declined dramatically. Assessments of the Personal Responsibility and Work Opportunity Reconciliation (PRWORA) of 1996 have focused heavily on the reduction of risks such as unemployment, young headship, nonmarriage, and births outside marriage (Cherlin et al. 2009; Fitzgerald and Ribar 2004; Lichter and Crowley 2004), leading many to deem these reforms successful (Bitler, Gelbach, and Hoynes 2006; Haskins and Sawhill 2003; Moffitt 2008). However, these assessments fail to test whether reductions in risks actually reduce poverty.

\section{THE PREVALENCE AND PENALTIES FRAMEWORK}

To better understand the relationship between risks and poverty, I examine both the prevalence of risks and the penalties associated with risks. Building on classical approaches to standardization and decomposition (Blinder 1973; Kitagawa 1955; Oaxaca 1973), Brady, Finnigan, and Hübgen (2017) argue that poverty is a function of both the share of the population having characteristics that increase the likelihood of poverty (i.e. the prevalence) and the increase in the probability of poverty associated with those characteristic (i.e. the penalties). The authors compare four major risks discussed above (low education, single motherhood, young headship, and unemployment) across 29 wealthy democracies, including the United States. Applying the prevalence and penalties framework, they find that despite having below average prevalence of risk factors, poverty in the U.S. is a result having the highest penalties of the 29 countries examined. The authors bolster these arguments using counterfactual simulations. Based on these estimates, they argue that, while reducing the prevalence of risk factors would largely be ineffective in reducing poverty in the U.S., reducing penalties would result in declines in poverty.

Working draft_-Please do not cite or quote without author's permission 
Using a similar framework, Laird and colleagues (2018) examine variations in poverty rates across U.S. states. While Brady and colleagues (2017) find that country-level variations in poverty are best explained by penalties, rather than prevalences, Laird et al. find that, at the state-level within the U.S, variation in poverty rates is closely tied to the prevalence of risks. Both studies concur that the prevalence of single motherhood is not the primary factor driving high poverty. In addition, while Brady (2017) discusses implications for ethno-racial differences, race is excluded from the primary analysis as a "risk" because a) race is an ascriptive characteristic and b) it cannot be reliably measured or operationalized cross-nationally. Within the U.S., Laird et al find that larger proportions of Black and Latino households are associated with increased poverty rates at the state-level. The authors conclude by cautioning that their results "do not suggest that state-level antipoverty policy should be solely focused on changing behavior" (Laird et al. 2018:647).

Two additional examples apply this framework to the study of child poverty. Examining multiple generations of immigration in the U.S., Thiede, Brooks, and Jensen (2020) find that limited parental employment is the largest risk factor for child poverty, more so than having a single, young, or low-educated parent. However, the magnitude of the penalties associated with risk factors varies across immigrant generations. Additionally, they find that a significant proportion of the gap in poverty between first or second-generation immigrants and third+ generation immigrants can be explained by prevalence of risk factors. Rothwell, Ottusch, and Finders (2019) examine children living in households with limited financial assets and find that asset poverty is higher in the U.S. than in other countries. Employing a key advantage of the framework, the authors leverage counterfactual decomposition methods to show that reducing the prevalence of single-parent female families in the U.S. would only reduce the poverty rate by an estimated 2.8 percentage points; thus, suggesting that high child asset poverty in the U.S. is driven by factors other than family structure.

\section{STRUCTURAL AND POLITICAL CONSIDERATIONS}

Working draft_-Please do not cite or quote without author's permission 
If ethno-racial differences in poverty cannot be explained through high prevalence of risks or disproportionately high penalties, alternative theories must be considered. Many scholars have shifted away from a focus on individual behaviors, increasingly focusing on structural and political factors (Brady 2019; Calnitsky 2018; Rank 2004). While behavioralists contend that ethno-racial differences are the result of culture or problematic behaviors, Williams (2019) argues that these differences are largely due to structural and political factors, including systemic racism.

Indeed, risks are largely shaped by structure. Previous scholarship has demonstrated that differences in poverty were shaped by changes in the labor market (Lichter, Qian, and Crowley 2005) and that employment differences were the largest contributing factor to the Black-white gap in poverty from 2010-2012 (Thiede, Lichter, and Sanders 2015). While past work has focused on family structure as a behavior, family composition is largely the result of policy and political structures (Hill 2006; Williams 2019). Furthermore, prior studies show white single-parent families have more wealth than married Black and Latino families (Hamilton et al. 2015; Traub 2017). Unemployment is another risk largely driven by structural factors. Extensive research demonstrates a strong relationship between employment and poverty (Williams 2019). Indeed, employment is the most salient predictor of both poverty (Brady et al. 2017) and child poverty (Regina S Baker 2015; Rainwater and Smeeding 2003). Variation in employment is an important factor in shaping racial inequality (Ray 2019; Sites and Parks 2011) and is conditioned by the labor market, at both the micro and macro levels.

A growing body of work demonstrates that racial discrimination plays a key role in labor market inequalities (Reskin 2012). Racial disparities feature strongly in unemployment, labor force participation, job assignments, wages and salary, promotions, working conditions, benefits, and daily experiences (Ray 2019; Reskin 2012; Wingfield and Chavez 2020). Black and Latino workers are both more likely to be unemployed compared to white workers and are more likely to work lowpaying jobs (Bureau of Labor Statistics 2020; Paul et al. 2018; Thiede et al. 2015). Compared to 
white applicants, Black and Latino applicants receive fewer job offers (Quillian, Lee, and Oliver 2020) and, when hired, are more likely to be over-qualified for the positions in which they are placed (Pager, Bonikowski, and Western 2009). Overall, Black and Latino applicants are consistently disadvantaged, even when accounting for education or criminal background (Gaddis 2015; Pager 2003). Furthermore, while there is some evidence of declining discrimination against Latinos over time, there is no evidence of change in anti-Black discrimination (Quillian et al. 2017).

At the macro-level, structural changes to labor markets disproportionately affect minoritized groups, which contributes to ethno-racial inequalities in poverty (Allard 2017; Calnitsky 2018; Rank 2004; Wilson 1987). Weak labor markets disproportionately disadvantage Black and Latino workers because they are often placed lower in hiring queues and tend to reside in locations further from well-compensated jobs (McCall 2001; Reskin 2012; Sites and Parks 2011). Large-scale economic changes have important implications for Black and Latino workers as deindustrialization, globalization, financialization, casualization, and increasing spatial and skill mismatches could all disproportionately worsen employment outcomes (Baker et al. 2020; Mouw 2000; Paul et al. 2018; Weller 2019; Wilson 1987).

Policy variation also plays an important role. Geographic spaces have defining ideologies and public policies that affect the economic outcomes of residents (Brady 2019; Michener 2018). Large Black and immigrant populations are associated with high levels of anti-Black and anti-immigrant sentiment among white residents (Browning, Dirlam, and Boettner 2016; King and Wheelock 2007). Variation in state welfare benefits and their conditions are influenced by racial heterogeneity (Bjorklund, Davis, and Pfaffendorf 2018). States with higher proportions of Black residents tend to de-prioritize the provision of cash assistance, preferring instead to fund programs that encourage marriage (Parolin 2019a). Finally, minoritized groups are more likely to live in the South, where unionization is low and social policies do little to address high poverty in the region (Baker 2020). 


\section{METHODS}

\section{Data}

The data are derived from the 1993-2016 Annual Social and Economic Supplement of the Census Bureau's Current Population Survey (CPS ASEC; also known as the "March Supplement"). The CPS ASEC is the same source used to calculate the U.S. Official Poverty Measure (OPM) as well as the Supplemental Poverty Measure (SPM). Recent studies indicate that respondents in the CPS underreport the value of means-tested transfers, such as income from the Supplemental Nutrition Assistance Program (SNAP) or and Temporary Assistance for Needy Families (TANF) (Heggeness et al. 2017; Meyer and Mittag 2019; Mittag 2019; Parolin 2019b) To correct for this underreporting I use the Urban Institute's Transfer Income Model (TRIM3). The TRIM uses HH data to predict the likelihood and amount of benefit receipt before staged micro-simulations match these estimates against administrative data to impute more accurate income estimates. Analyses are weighted to represent the US population. ${ }^{2}$ A vast sample of data collected from $1992-2015^{3}$ helps lend confidence to robust estimations. This marks the earliest year to the most recent year the TRIM corrections are available at the time of writing. The unit of analysis for this study is the individual. The full sample size is 4,293,237 individuals across 24 years, while the analytical sample, which is restricted to individuals in $\mathrm{HHs}$ with heads under the age of 65 , is $3,552,092 .{ }^{4}$ Of these individuals, 2,472,745 are in white-lead HHs, 416,271 are in Black-lead HHs, and 663,076 are in Latino-lead HHs.

${ }^{2}$ Unweighted analyses produce similar results.

3 1993-2016 refers to the survey years, while 1992-2015 refer to the collection years. For example, CPS data released in 2016 represents information collected in 2015.

${ }^{4}$ The CPS data over the 24 years results in greater than 4 million observations. TRIM estimates for each year must be downloaded and merged into the existing CPS data at the individual and household levels. Once this stage was complete, poverty rates, prevalences, and penalties were estimated using sets of nested loops that spanned fifty states over 24 years, resulting in over 1,200 state-years for three separate groups. Altogether, over 5,000 models were estimated in data creation.

Working draft—Please do not cite or quote without author's permission 


\section{Dependent Variables}

The dependent variable is poverty. Following the vast majority of international poverty research (e.g. Baker 2015; Brady, Finnigan, and Hübgen 2017; Chen and Corak 2008; Rainwater and Smeeding 2003), relative poverty is operationalized as those residing in HHs with less than 50\% of median equivalized disposable $\mathrm{HH}$ income (DHI). The poverty threshold is based on the national median each year, giving each state the same temporally relative threshold. DHI is calculated following widely-used standards (Parolin 2019b; Rainwater and Smeeding 2003; Smeeding 2016) and incorporates all taxes and transfers (including SNAP and EITC), matching the measurement protocol of the Luxembourg Income Study (LIS). DHI is adjusted household size for (i.e. "equivalized") by dividing by the square-root of the number of members in the household. This approach represents the state of the art in the field using high quality data, greatly improving upon the definition of income used in the estimation of the OPM. ${ }^{5}$

\section{Risk Variables}

Following previous applications of the prevalence and penalties framework, this study focuses on the four most important risks of poverty for working-aged HHs (i.e., HHs headed by those under 65 years old): single motherhood, low education, young headship, and unemployment. The lead earner of the HH (hereafter the "lead") represents the adult with the highest labor market earnings with ties broken by highest age (Brady, Baker, and Finnigan 2013). ${ }^{6}$ Young lead includes those in a

\footnotetext{
${ }^{5}$ The OPM was established with little scientific basis over 50 years ago, which means the current thresholds are widely understood to be too low. Furthermore, the OPM ignores taxes and tax credits, while inconsistently including transfer incomes. For example, while income from the EITC is not included, social security pensions are. The OPM also ignores state tax and tranfers, creating additional issues with validity and reliability.

${ }^{6}$ The term "lead" is used in place of "head." In the CPS data, the variable "relate" indicates one's relation to the "head of the household." However, the head is often an ideological head and, in the past, has defaulted to the husband in a heterosexual, married household, regardless of income or family structure. Thus, "lead" indicates the lead earner of the household, rather than the more
} 
$\mathrm{HH}$ with a lead earner under 25 years old. Single motherhood is defined as those living in a HH lead by an unmarried and unpartnered woman who resides with children under age 18. Low education is measured as residing in a $\mathrm{HH}$ where the lead has less than a high school diploma. Unemployed HHs are those in which no members are employed ${ }^{7}$.

\section{Race and Ethnicity Variables}

Self-reported measures of race and ethnicity from the CPS are used to examine differences in poverty, prevalences, and penalties between individuals living in white-, Black-, and Latino-lead HHs. Three mutually exclusive categories are formed based on these responses. An individual is coded as white if they identify as white only and Black if they identify as Black only. If an individual identifies as Latino, they are categorized as Latino-only, creating an exclusive category. Thus, white or Black respondents are non-Latino white or Black respondents. While the unit of analysis is the individual, an individual's race is not included as a control variable. Rather, models are estimated separately on white-lead HHs, Black-lead HHs, and Latino-lead HHs and are formally tested for differences in coefficients with Black and Latino HHs each compared to white HHs.

\section{Key Independent Variables}

A set of independent variables is included based on previous research on poverty (Brady and Bostic 2015; Brady et al. 2017; Rainwater and Smeeding 2003; Vandecasteele 2011). These covariates include indicators for $\mathrm{HHs}$ with leads 25-34 years old and $\mathrm{HH}$ with leads over 54, female-lead no child $H H s$, male-lead no child $H H s$, dual-earner $H H s$, and high education $H H s$. High education is indicated by a

abstract "head" (see https://www.census.gov/programs-surveys/cps/technicaldocumentation/subject-definitions.html for more information).

${ }^{7}$ The CPS defines as "employed" those who worked at least 1 hour as a paid employee; worked at least 1 hour in their own business, profession, trade, or farm; were temporarily absent from their job, business, or farm, whether or not they were paid for the time off; or worked without pay for a minimum of 15 hours in a business or farm owned by a member of their family.

Working draft_-Please do not cite or quote without author's permission 
lead with a college degree or greater. Count variables for the number of children under 18 and the number of adults over 64 in the $\mathrm{HH}$ are also included.

\section{Analytic Strategy}

The analysis involves four stages to examining ethno-racial differences in poverty, including: (1) testing for differences in poverty rates, (2) estimation of linear probability models (LPMs) of poverty, (3) descriptive analysis and statistical testing for differences in prevalences and penalties, and (4) counterfactual estimates of poverty. Used in conjunction, these approaches form a robust analysis and provide insight into the factors associated with ethno-racial differences in poverty.

Poverty rates are examined descriptively over time and the differences between Black and Latino poverty rates are statistically tested. LPMs of poverty are estimated using the variables discussed above. The LPMs are fully interacted, having been estimated separately on the three populations of interest (white, Black, and Latino-lead HHs). Prevalences are estimated as the proportion of the population with a given risk (including sample weights), while penalties are defined as the increase in the probability of poverty associated with a risk (Brady et al. 2017). To derive penalties, linear probability models are first estimated using the four primary risks and controls described below to predict poverty. ${ }^{8}$ The coefficient associated with each of the four risks indicate the increase in the probability of the outcome (poverty). These values are extracted to populate the penalty variable associated with each risk. Linear probability models are preferable in this instance because neither logistic regression coefficients nor odds ratios can be compared across models or samples (Allison 1999; Breen, Karlson, and Holm 2018), which is a central component of this

\footnotetext{
${ }^{8}$ While average marginal effects could be used to compare risks, counterfactual estimates are not concordant. As counterfactual estimates are central to this analysis, AMEs are not included. However, substantive results without counterfactual estimates are similar.
} 
study. ${ }^{9}$ Robust standard errors clustered on $\mathrm{HHs}$ are used to correct heteroskedasticity inherent in linear probability models. Differences in both the prevalences of and the penalties associated with the four risk factors between are statistically tested, with individuals in Black or Latino-lead HHs compared to individuals in white-lead HHs.

The final step in the analysis is the estimation of poverty rates given counterfactual prevalences and penalties for the four risk factors. First, poverty is estimated as discussed above, then the same model is estimated using an alternative value for one of the risk variables. For example, poverty is estimated for individuals in Black-lead HHs using the values observed in the data, then the value for one of the risk variables (e.g. single mother lead) is replaced with the value observed in the data for white-lead HHs. The result is the predicted poverty rate given the counterfactual prevalence. The predicted poverty rates are then formally tested for statistically significant differences.

\section{RESULTS}

\section{Differences in Poverty Rates}

Before examining the role of risk prevalences and penalties, I first highlight descriptive trends in poverty. Consistent with previous work using both the OPM and other measures, my analysis of 3,552,092 individuals confirms large disparities in the poverty rates of individuals living in white, Black, and Latino-lead HHs. Figure 1 illustrates trends in poverty derived from the data used in this paper. Over the course of the data, Black and Latino poverty rates are over $250 \%$ of the white poverty rate. In 1993, the poverty rate for white individuals was around 12 percent, while Black and Latino poverty rates were around 33 and 30 percent, respectively. When compared to

\footnotetext{
${ }^{9}$ Linear probability models offer several other advantages. In addition to being less computationally intensive when using large datasets, LPM models are expected to be less biased and more consistent than logit or probit models when probabilities fall within the interval range (0-1), as they do in this analysis (Horrace and Oaxaca 2006).
} 
whites individuals, this equates to differences in the poverty rate of 21 percentage points for Black individuals and 18 percentage points for Latino individuals. While poverty has decreased for Black and Latino Americans over the past two decades, in 2016 poverty was twice as high among Black and Latino individuals at around 26 percent and 23 percent respectively, when compared to around 11.5 percent for white individuals. The differences in white, Black, and Latino poverty rates remained sizeable at around 15 percentage points higher for Black individuals and 11 percent points for Latino individuals compared to white individuals.

\section{[INSERT FIGURE 1 ABOUT HERE]}

\section{Differences in the Prevalence of Risk Factors}

Next, I examine differences in the prevalence of risk factors between individuals living in white, Black, and Latino lead HHs. Substantial differences in the prevalence of risk factors may explain differences in poverty rates. Figure 2 shows prevalence of the four primary risks over time. Overall, prevalences of these risk factors have declined for all three groups examined.

\section{[INSERT FIGURE 2 ABOUT HERE]}

The prevalence of individuals living in low-educated lead HHs is the highest overall. Over the course of the data, $6.3 \%$ of white, $13.5 \%$ of Black, and $36.6 \%$ of Latino respondents living in households with leads having less than a high school diploma. However, as seen in Figure 2A, the risk of low educated leads has declined for all three groups, with prevalence declining 5 percentage points for individuals in white lead HHs, 11.6 percentage points for individuals in Black lead HHs, and 14.7 percentage points for individuals in Latino lead HHs, down from $42.8 \%$ in 1993 to $28.1 \%$ in 2016.

Single motherhood is the next most common risk. $24.9 \%$ of individuals living in Black lead HHs, $12.29 \%$ of individuals living in Latino lead HHs and $6.8 \%$ of individuals living in white lead $\mathrm{HH}$ also live in $\mathrm{HH}$ headed by single mothers. However, as seen in Figure $2 \mathrm{~B}$ prevalence in Black 
lead HHs has declined the most sharply in absolute terms, dropping 10.46 percentage points since 1993, while single mother leads dropped 4.2 points in Latino HHs and remained relatively stable in white HHs, dropping 0.63 points.

The prevalence of leads under 25 is low, with no group averaging a prevalence greater than ten percent over the course of the data. Only $4.88 \%$ of white individuals, $7.82 \%$ of Black individuals, and $8.51 \%$ of Latino individuals livened in $\mathrm{HHs}$ with young leads. Additionally, as seen in Figure 2C, while the prevalence of young leads among white lead HHs has remained relatively stable, the prevalence has decreased in Black and Latino lead HHs.

The prevalence of unemployed $\mathrm{HHs}^{10}$ is relatively low as well, with individuals living in Black HHs having the highest prevalence at $12.4 \%$ on average over the course of the data. Individuals in white and Latino lead HHs have similar prevalences, with differences that are either very small or statistically insignificant, averaging $5.31 \%$ and $5.85 \%$ respectively. Figure $2 \mathrm{D}$ shows prevalences in both Black and Latino lead HHs declined in the late 90s but have remained relatively stable since.

\section{[INSERT TABLE 1 ABOUT HERE]}

\section{Differences in the Penalties Associated with Risk Factors}

Table 1 shows the results of the linear probability models for white, Black, and Latino lead HHs. Following the prevalences-penalties framework, penalties are the "greater probabilities of poverty associated with a given risk" (Brady et al. 2017:743). Thus, in the linear probability models, the coefficients for the four risks (young lead, single mother, low education, unemployed) can be interpreted as the difference in the probability of poverty conditioned on the covariates. Probabilities range from 0 to 1 and are multiplied by 100 to ease interpretation of probabilities.

\footnotetext{
${ }^{10}$ As a reminder, this refers to $\mathrm{HH}$ shere no person in the $\mathrm{HH}$ is employed.
} 
Differences are statistically significant, unless otherwise noted (with Black and Latino lead HHs each compared to white lead HHs).

\section{[INSERT FIGURE 3 ABOUT HERE]}

Single motherhood carries the lowest penalty across all groups. Single mother leads in white HHs are associated with a 11.63 percentage point increase in the probability of poverty, while the increase is 10.23 percentage points for individuals in Black lead HHs and 6.76 percentage points in Latino lead HHs. Figure 3 shows these penalties over time. As seen in Fig 3A, while the penalty for those in white lead HHs has remained stable over the course of the data, the penalty for those in Black lead HHs has dropped from 14.15 percentage points in 1993 to 7 percentage points in 2016 and has risen for those in Latino HHs to 6.3 percentage points in 2016, up from 5.6 percentage points in 1993.

Penalties for individuals in young lead HHs are similar across all groups. Those in Black lead HHs have the highest penalty with a 17.35 percentage point increase in the probability of poverty. While those in Latino lead HHs have an average penalty of 13.57 percentage points and those in white lead HHs have an average penalty of 14.34 percentage points, the difference between the two is not statistically significant over the course of the data $\left(X^{2}=2.73 ; p=.0986\right)$. As seen in Figure 3B, the penalty for individuals in Black lead HHs with young leads has increased in recent years, going from 14.26 percentage points in 2012 to 19.71 percentage points in 2016.

The penalty for individuals in HHs having leads with low education is the most similar across groups. Black leads with less than a high school diploma are associated with a 16.82 percentage point increase in the probability of poverty. The average penalty is 15.45 percentage points for individuals in white lead HHs and 15.83 percentage points for individuals in Latino HHs, but this difference is not statistically significant over the course of the data $\left(X^{2}=1.32 ; \mathrm{p}=.2508\right)$. As seen in Figure 3C, the penalties for all groups have been relatively stable over the course of the data,

Working draft_-Please do not cite or quote without author's permission 
although the penalty for Black lead HHs increased from 14.69 percentage points in 1993 to 17.54 percentage points in 2016.

Unemployment carries the most injurious penalty across all groups. For individuals in Latino lead HHs with no one in the labor force, the probability of poverty increases by 28.68 percentage points. This penalty increases to 31.83 percentage points for those in white lead HHs and 34 percentage points for those in Black lead HHs. Figure 3D shows this penalty over time. Unlike the penalties previously discussed, the penalty for unemployment has increased for all groups over the course of the data. High penalties for unemployment may be taken for granted in the US; however, countries such as Denmark, Luxembourg, and the Netherlands all have penalties below 15 percentage points, while those in unemployed HHs in Iceland have no significant increase in the probability of poverty (Brady et al. 2017). High penalties in the US may be a result of policy such as the Earned Income Tax Credit (EITC), where transfer resources are predicated on and proportional to labor market income.

\section{Do Risks Explain Differences in Poverty?}

The effect of counterfactual prevalences and penalties is simulated to assess whether risks (i.e. individual behaviors) explain differences in poverty rates between white, Black, and Latino HHs. Poverty is predicted using the linear probability models described above. Next, values representing counterfactual prevalences are substituted in the model to predict poverty under alternative conditions. Counterfactuals penalties for the risks are also used to predict poverty given alternative contexts. Unless otherwise specified, all counterfactuals are statistically significantly different from the predicted poverty rates produced by the linear probability models. ${ }^{11}$

${ }^{11}$ Based on t-tests of means.

Working draft_-Please do not cite or quote without author's permission 
This approach builds upon classic techniques of decomposition and standardization (Blinder 1973; Kaufman 1983; Kitagawa 1955; Oaxaca 1973; Treiman 2014:175). Scholars of poverty and inequality have employed similar techniques to examine group differences (Bernardi and Boertien 2017; Brady et al. 2017; Gornick and Jäntti 2012; Heuveline and Weinshenker 2008; Rainwater and Smeeding 2003). I extend these approaches first by examining counterfactual risks both individually and simultaneously and second by going beyond assessing only prevalence of risks and examining counterfactual penalties as well.

\section{[INSERT FIGURE 4 ABOUT HERE]}

\section{Reducing the Prevalence of Risks}

To begin, I examine what poverty rates for individuals in Black lead HHs would look like given the prevalence of risks found in white lead HHs. Leads under 25 are uncommon in both white and Black lead HHs. Reducing the prevalence of young leads in Black lead HHs would reduce poverty by only one-half of a percentage point (.51). The prevalence of low-educated leads is also small in both white and Black lead HHs, although somewhat higher in Black HHs. Reducing prevalence in Black lead HHs would result in a predicted decrease of 1.21 percentage points. The largest difference between white and Black HHs is the prevalence of single mother lead HHs, with a difference of just over 18 percentage points. If the prevalence of single mother leads in Black lead HHs was reduced to the level of white lead HHs, the effect on poverty would be an estimated reduction of 1.91 percentage points. The largest decrease in predicted poverty would be realized in reducing the number of unemployed HHs. This would result in an estimated reduction of 2.41 percentage points.

When combined, these figures can offer insights regarding what poverty would look like if the prevalence of risk factors in Black lead HHs was the same as those in white lead HHs. If the prevalence of the four primary risk factors in Black lead HHs was equal to the prevalence found in 
white lead $\mathrm{HHs}$, the result would be an estimated 6.05 percentage point decrease in poverty. This reduction would result in a Black poverty rate of approximately 20.19 percent, which is more than 10 percentage points higher than the poverty rate for white individuals. We can also estimate the effect of eliminating risks in Black lead HHs altogether. The result would be an estimated reduction in poverty of 10.4 percentage points. Even with this reduction, the predicted Black poverty rate (15.83 percent with zero prevalence of risk factors) would remain over 5 percentage points higher than the actual white poverty rate (9.9 percent).

This procedure is repeated for individuals in Latino lead HHs. The least prevalent risk among individuals in Latino lead HHs is unemployment. Reducing the prevalence of HHs in which no one is employed to the level of white HHs would reduce poverty by an estimated 0.16 percentage points. The prevalence of single mother lead HHs is also relatively low. Reducing the prevalence in Latino leads $\mathrm{HHs}$ to that of white $\mathrm{HHs}$ would result in an estimated reduction in poverty of 0.37 percentage points. The prevalence of young lead HHs in Latino lead HHs is similar to that of Black HHs. If the prevalence were reduced to that of white HHs the estimated reduction in poverty would be 0.5 percentage points. The prevalence of leads with less than a high school diploma is substantially higher in Latino lead HHs than in Black or white lead HHs. If the prevalence of young leads in Latino lead HHs was reduced to the level found among white HHs the result would be an estimated decrease in poverty of 4.8 percentage points.

Overall, if Latino lead HHs had the same prevalence of risk factors as white lead HHs, the estimated total reduction in poverty would be approximately 5.8 percentage points. Despite this reduction, Latino poverty would be nearly twice white poverty at 18.55 percent compared to 9.9 percent. Furthermore, if the prevalence of all four risk factors was reduced to zero, the estimated reduction in poverty would be 9.45 percentage points. The estimated poverty level of approximately 
14.9 percent would remain 5 percentage points higher than the poverty rate for individuals in white lead HHs.

Reducing the Penalties of Risks

While reducing penalties overall would result in substantial decreases in poverty in the US (Brady et al. 2017), differences in penalties do not account for much of differences in poverty between white leads HHs and Black and Latino leads HHs. If the penalties for low educated leads, young leads, and unemployed HHs, were equal for Black lead and white lead HHs, these changes would result in decreases of 0.19 percentage points, 0.24 percentage points, and 0.27 percentage points, respectively. The penalty for single mother leads is slightly higher for white lead HHs than Black lead HHs. Matching the penalty for white lead HHs would result in an increase in poverty of .34 percentage points for Black HHs. Overall, if penalties were equal for Black lead HHs compared to white lead HHs, poverty would be reduced by an estimated one third of a percentage point (0.35).

The results are similar for Latino lead HHs. The penalties associated with both young and low educated leads is not significantly different for white and Latino lead HHs. The penalties for single mother leads and unemployed HHs are both slightly higher for white lead HHs, compared to Latino lead HHs. Thus, if Latino lead HHs were penalized at the same level as white lead HHs, the result would be estimated increases of 0.6 percentage points and .18 percentage points, respectively. Overall, if penalties were the same for Latino lead HHs for white HHs, the result would be an estimated .71 percentage point increase in the poverty rate.

Finally, alternative penalties can be combined with the alternative prevalences discussed above. If Black lead HHs had the same prevalence of risk factors and were penalized at the same level as white lead HHs, the predicted poverty rate would decrease by 6.3 percentage points. The resulting poverty rate of 19.93 percent would still be 10 percentage points higher than the poverty rate for individuals in white lead HHs. For Latino lead HHs, if prevalences and penalties associated 
with the four risks were equal to those in white lead HHs, the poverty rate would be an estimated 5.3 percentage points lower. The resulting estimated poverty rate of 19.06 percent would be nearly twice the poverty rate of white lead HHs with observed prevalences and penalties.

\section{CONCLUSION}

Ethno-racial differences in poverty remain a critical issue for scholars of inequality. Previous studies rely largely on behavioral explanations to explain high poverty and ethno-racial differences. According to these approaches, poverty results from behaviors which increase the likelihood of poverty and ethno-racial differences are explained by a disproportionately high prevalences of these behaviors in Black and Latino populations. However, these approaches rely heavily on untested assumptions regarding the relationship between behaviors (or risks) and poverty.

This study examines ethno-racial differences in poverty in the United States from 1993-2016 using data from the Current Population Survey and the Urban Institute's TRIM3 model to derive high-quality estimates of income and poverty, which incorporate taxes and transfers and account for benefit underreporting. This approach represents the most recent advances in poverty estimation and improves greatly upon estimates based on the OPM. I confirm that ethno-racial differences in poverty are persistent and substantial. Over the course of the data, the poverty rates for Black and Latino individuals is $250 \%$ of the poverty rate experienced by white individuals. While poverty for Black and Latino Americans has decreased over the past two decades, poverty was twice as high among Black and Latino individuals at around 26 percent and 23 percent respectively, when compared to around 11.5 percent for white individuals in 2016.

A framework of prevalences and penalties is used to examine the role of risks in poverty among Black, Latino, and white individuals. This framework is leveraged to predict poverty levels given counterfactual risk prevalences and penalties and to determine if behavior can explain ethnoracial differences in poverty. Black individuals are more likely to live in homes with single mother 
leads, with a difference of just over 18 percentage points compared to white individuals in the data. If the prevalence in both groups were equal, the estimated effect is a reduction of 1.91 percentage points in predicted poverty. For individuals in Latino-lead HHs, the prevalence of leads with less than a high school diploma is substantially higher than for those in white lead HHs. If the prevalence of young leads was reduced to the level found among white HHs the result would be an estimated decrease in poverty of 4.8 percentage points for Latino individuals.

While these findings demonstrate that risks play a small role in reducing poverty, the ethnoracial differences overwhelmingly persist. To highlight this point, I estimate poverty levels given a complete elimination of risks for Black and Latino individuals. The resulting poverty rates for Black and Latino individuals would each remain around 5 percentage points higher than poverty in white individuals with observed levels of risks. In other words, even if the four most widely studied risk behaviors were completely eliminated from the Black and Latino populations, we should still expect to observe poverty rates higher than those observed for white individuals.

These findings seriously undermine behavioral explanations of poverty. If poverty is the result of problematic behaviors, then groups with similar prevalences of risk behaviors should have similar poverty rates. This is not supported by the data. In fact, even when prevalences are lower in Black and Latino HHs, these individuals are still significantly more likely than white individuals to experience poverty. This highlights the need to redirect work that focuses on risk behaviors via family structure, culture, etc. While reducing these risks has small effects on poverty, these reductions are limited and do not provide a path to ethno-racial equity. The large residual differences that remain even after assuming full elimination of risk behaviors necessitates a shift toward explanations that consider the role of structural and political considerations, including racism.

Future research can address some of the limitations of this analysis. While this analysis provides strong evidence that behavioral explanations fail to explain ethno-racial differences in 
poverty, testing alternative theories is beyond the scope of this study. Based on the analyses presented, future work should examine structural and political-economic contexts. In countries with more generous welfare policies, the associations between risks and poverty weaken (Brady et al. 2017). Power Resources Theory (PRT) provides an opportunity for scholars to examine the extent to which unions and left-party policies help to implement redistributive policies (Bradley et al. 2003; Brady et al. 2013; Kelly and Witko 2012; Korpi 1983) and whether these policies benefit ethno-racial groups similarly or whether these policies disproportionately benefit white recipients. In addition, while little variation is found in the penalties associated with the risks across white, Black, and Latino lead HHs at the national level, it is likely greater variation would be observed at the state-level. Work such as Baker's (2020; 2015) imply that, along with historical contexts, the political-economic contexts of some states, such as those in the South, would result if harsher penalties for Black Americans compared to whites. A study implemented at the regional or state-level could increase granularity and allow scholars to determine if ethno-racial differences are the result of Black and Latino populations being concentrated in areas with high penalties, for example. Finally, scholars should put a much greater emphasis on examining the role of systemic racism is shaping racially disparate outcomes. The largest reductions in poverty for Black and Latino individuals come from reducing unemployment and low education, respectively. However, as demonstrated, even eliminating these risks does not eliminate differences in poverty compared to whites. For both Black and Latino Americans, quality of employment may play an important role. Discrimination in hiring, resulting in reduced wages and underemployment could mean that even employed People of Color are more likely to experience poverty. Scholars should examine the extent to which various embodiments of systemic racism affect the ability of Black and Latino Americans to avoid poverty. In terms of policy, these findings demonstrate the shortcomings of policy focused on riskreductions. If policy is intended to reduce poverty, the benchmark used to assess the success of said 
policy should be the extent to which poverty is reduced, not the extent to which a proxy measure, such as a risk, is reduced. Addressing poverty through risk reduction is inefficient and largely ineffective. Furthermore, as demonstrated by this study, eliminating ethno-racial differences in poverty by focusing on behaviors is a futile pursuit. 


\section{REFERENCES}

AEI-Brookings. 2015. Opportunity, Responsibility, and Security: A Consensus Plan for Reducing Poverty and Restoring the American Dream. Washington, DC.

Allard, Scott W. 2017. Places in Need: The Changing Geography of Poverty. Russell Sage Foundation.

Allison, Paul D. 1999. “Comparing Logit and Probit Coefficients across Groups." Sociological Methods \& Research 28(2):186-208.

Baker, Regina S. 2015. “The Changing Association among Marriage, Work, and Child Poverty in the United States, 1974-2010.” Journal of Marriage and Family 77(5):1166-78.

Baker, Regina S. 2020. "Why Is the American South Poorer?” Social Forces 99(1):126-54.

Baker, Regina S., David Brady, Zachary Parolin, and Deadric T. Williams. 2020. The Enduring Significance of Ethno-Racial Inequalities in Poverty in the US, 1993-2017.

Baker, Regina Smalls. 2015. "Poverty and Place in the Context of the American South."

Bernardi, Fabrizio and Diederik Boertien. 2017. "Non-Intact Families and Diverging Educational Destinies: A Decomposition Analysis for Germany, Italy, the United Kingdom and the United States." Social Science Research 63:181-91.

Bertrand, Marianne, Sendhil Mullainathan, and Eldar Shafir. 2004. “A Behavioral-Economics View of Poverty." American Economic Review 94(2):419-23.

Bitler, Marianne P., Jonah B. Gelbach, and Hilary W. Hoynes. 2006. "Welfare Reform and Children's Living Arrangements.” Journal of Human Resources 41(1):1-27.

Bjorklund, Eric, Andrew P. Davis, and Jessica Pfaffendorf. 2018. "Urine or You're out: Racialized Economic Threat and the Determinants of Welfare Drug Testing Policy in the United States, 2009-2015." The Sociological Quarterly 59(3):407-23.

Blinder, Alan S. 1973. "Wage Discrimination: Reduced Form and Structural Estimates.” Journal of Human Resources 436-55.

Bloome, Deirdre. 2017. "Childhood Family Structure and Intergenerational Income Mobility in the United States.” Demography 54(2):541-69.

Du Bois, William Edward Burghardt. 2008. The Souls of Black Folk. Oxford University Press.

Bradley, David, Evelyne Huber, Stephanie Moller, François Nielsen, and John D. Stephens. 2003. "Distribution and Redistribution in Postindustrial Democracies." World Politics 55(02):193-228.

Brady, David. 2019. "Theories of the Causes of Poverty." Annual Review of Sociology 45:155-75.

Brady, David, Regina Baker, and Ryan Finnigan. 2013. "When Unionization Disappears: State-Level Unionization and Working Poverty in the United States." American Sociological Review 78(5):87296.

Brady, David and Amie Bostic. 2015. "Paradoxes of Social Policy Welfare Transfers, Relative Poverty, and Redistribution Preferences." American Sociological Review 80(2):268-98.

Brady, David, Ryan M. Finnigan, and Sabine Hübgen. 2017. "Rethinking the Risks of Poverty: A Framework for Analyzing Prevalences and Penalties." American Journal of Sociology 123(3):740_

Working draft_-Please do not cite or quote without author's permission 
86.

Breen, Richard, Kristian Bernt Karlson, and Anders Holm. 2018. "Interpreting and Understanding Logits, Probits, and Other Nonlinear Probability Models.” Annual Review of Sociology 44:39-54.

Browning, Christopher R., Jonathan Dirlam, and Bethany Boettner. 2016. "From Heterogeneity to Concentration: Latino Immigrant Neighborhoods and Collective Efficacy Perceptions in Los Angeles and Chicago." Social Forces 95(2):779-807.

Bureau of Labor Statistics. 2020. The Employment Situation—December 2020.

Calnitsky, David. 2018. "Structural and Individualistic Theories of Poverty." Sociology Compass 12(12):e12640.

Chen, Wen-Hao and Miles Corak. 2008. "Child Poverty and Changes in Child Poverty." Demography 45(3):537-53.

Cherlin, Andrew, Bianca Frogner, David Ribar, and Robert Moffitt. 2009. "Welfare Reform in the Mid-2000s: How African American and Hispanic Families in Three Cities Are Faring." The Annals of the American Academy of Political and Social Science 621(1):178-201.

Citro, Constance F. and Robert T. Michael. 1995. Measuring Poverty: A New Approach. Washington, DC: National Academies Press.

Council of Economic Advisers. 2014. The War on Poverty 50 Years Later: A Progress Report. Executive Office of the President of the United States, Council of Economic ....

Cruz, Marcio and S. Amer Ahmed. 2018. "On the Impact of Demographic Change on Economic Growth and Poverty.” World Development 105:95-106.

Dahl, Gordon B., Andreas Ravndal Kostøl, and Magne Mogstad. 2014. "Family Welfare Cultures." The Quarterly Journal of Economics 129(4):1711-52.

Durlauf, Steven N. 2011. “Groups, Social Influences, and Inequality.” Pp. 141-75 in Poverty Traps. Princeton, NJ: Princeton University Press.

Ellwood, David T. and Christopher Jencks. 2004. "The Uneven Spread of Single-Parent Families: What Do We Know? Where Do We Look for Answers.” Social Inequality 1:3-77.

Fitzgerald, John M. and David C. Ribar. 2004. "Welfare Reform and Female Headship.” Demography 41(2):189-212.

Fox, Liana, Christopher Wimer, Irwin Garfinkel, Neeraj Kaushal, JaeHyun Nam, and Jane Waldfogel. 2015. "Trends in Deep Poverty from 1968 to 2011: The Influence of Family Structure, Employment Patterns, and the Safety Net.” RSF: The Russell Sage Foundation Journal of the Social Sciences 1(1):14-34.

Gaddis, S. Michael. 2015. "Discrimination in the Credential Society: An Audit Study of Race and College Selectivity in the Labor Market." Social Forces 93(4):1451-79.

Gennetian, Lisa A. and Eldar Shafir. 2015. "The Persistence of Poverty in the Context of Financial Instability: A Behavioral Perspective." Journal of Policy Analysis and Management 34(4):904-36.

Gornick, Janet C. and Markus Jäntti. 2012. "Child Poverty in Cross-National Perspective: Lessons

Working draft—Please do not cite or quote without author's permission 
from the Luxembourg Income Study." Children and Youth Services Review 34(3):558-68.

Hamilton, Darrick, William Darity Jr, Anne E. Price, Vishnu Sridharan, and Rebecca Tippett. 2015. "Umbrellas Don't Make It Rain: Why Studying and Working Hard Isn't Enough for Black Americans." New York: The New School.

Hannum, Emily and Yu Xie. 2016. "Education." Pp. 462-85 in The Oxford handbook of the social science of poverty., edited by B. and Burton. New York, NY: Oxford University Press.

Harding, David J. 2007. "Cultural Context, Sexual Behavior, and Romantic Relationships in Disadvantaged Neighborhoods.” American Sociological Review 72(3):341-64.

Harding, David J. 2010. Living the Drama: Community, Conflict, and Culture among Inner-City Boys. University of Chicago Press.

Harding, David J. 2011. "Rethinking the Cultural Context of Schooling Decisions in Disadvantaged Neighborhoods: From Deviant Subculture to Cultural Heterogeneity." Sociology of Education 84(4):322-39.

Haskins, Ron. 2009. "Moynihan Was Right: Now What?" The Annals of the American Academy of Political and Social Science 621(1):281-314.

Haskins, Ron and Isabel V Sawhill. 2003. Work and Marriage: The Way to End Poverty and Welfare. Welfare Reform \& Beyond Initiative, Brookings Institution.

Heggeness, Misty L., Liana Fox, Jose Pacas, and Kathryn Stevens. 2017. "Precision in Measurement: Using SNAP Administrative Records to Evaluate Poverty Measurement." Association for Public Policy Analysis and Management (APPAM) 2017 Fall Research Conference 49.

Heuveline, Patrick and Matthew Weinshenker. 2008. "The International Child Poverty Gap: Does Demography Matter?” Demography 45(1):173-91.

Horrace, William C. and Ronald L. Oaxaca. 2006. "Results on the Bias and Inconsistency of Ordinary Least Squares for the Linear Probability Model.” Economics Letters 90(3):321-27.

Iceland, John. 2013. Poverty in America: A Handbook. Univ of California Press.

Iceland, John. 2019. "Racial and Ethnic Inequality in Poverty and Affluence, 1959-2015." Population Research and Policy Review 38(5):615-54.

Kaida, Lisa. 2015. "Ethnic Variations in Immigrant Poverty Exit and Female Employment: The Missing Link.” Demography 52(2):485-511.

Kaufman, Robert L. 1983. "A Structural Decomposition of Black-White Earnings Differentials.” American Journal of Sociology 89(3):585-611.

Kelly, Nathan J. and Christopher Witko. 2012. "Federalism and American Inequality." Journal of Politics 74(2):414-26.

King, Ryan D. and Darren Wheelock. 2007. "Group Threat and Social Control: Race, Perceptions of Minorities and the Desire to Punish.” Social Forces 85(3):1255-80.

Kitagawa, Evelyn M. 1955. “Components of a Difference between Two Rates.” Journal of the American Statistical Association 50(272):1168-94.

Working draft—Please do not cite or quote without author's permission 
Kohler, Ulrich, Martin Ehlert, Britta Grell, Jan Paul Heisig, Anke Radenacker, and Markus Wörz. 2012. "Verarmungsrisiken Nach Kritischen Lebensereignissen in Deutschland Und Den USA." Kolner Zeitschrift Fur Soziologie Und Sozialpsychologie 64(2):223-45.

Korpi, Walter. 1983. The Democratic Class Struggle. Routledge.

$\mathrm{Ku}$, Inhoe, Wonjin Lee, Seoyun Lee, and Kyounghoon Han. 2018. "The Role of Family Behaviors in Determining Income Distribution: The Case of South Korea.” Demography 1-23.

Laird, J., Z. Parolin, J. Waldfogel, and C. Wimer. 2018. "Poor State, Rich State: Understanding the Variability of Poverty Rates Across U.S. States." Sociological Science 5.

Lichter, Daniel T. and Martha L. Crowley. 2004. "Welfare Reform and Child Poverty: Effects of Maternal Employment, Marriage, and Cohabitation.” Social Science Research 33(3):385-408.

Lichter, Daniel T., Zhenchao Qian, and Martha L. Crowley. 2005. "Child Poverty among Racial Minorities and Immigrants: Explaining Trends and Differentials.” Social Science Quarterly 86:1037-59.

Lin, Ann Chih and David R. Harris. 2008. The Colors of Poverty: Why Racial and Ethnic Disparities Persist. Russell Sage Foundation.

Ludwig-Dehm, Sarah M. and John Iceland. 2017. "Hispanic Concentrated Poverty in Traditional and New Destinations, 2010-2014.” Population Research and Policy Review 36(6):833-50.

Martinez, Gladys, Kimberly Daniels, and Anjani Chandra. 2012. Fertility of Men and Women Aged 1544 Years in the United States: National Survey of Family Growth, 2006-2010. Department of Health and Human Services, Centers for Disease Control and ....

McCall, Leslie. 2001. "Sources of Racial Wage Inequality in Metropolitan Labor Markets: Racial, Ethnic, and Gender Differences." American Sociological Review 520-41.

McEwen, Craig A. and Bruce S. McEwen. 2017. "Social Structure, Adversity, Toxic Stress, and Intergenerational Poverty: An Early Childhood Model.” Annual Review of Sociology 43:445-72.

McLanahan, Sara. 2009. "Fragile Families and the Reproduction of Poverty." The Annals of the American Academy of Political and Social Science 621(1):111-31.

McLoyd, Vonnie C., Rosanne M. Jocson, and Abigail B. Williams. 2016. "Linking Poverty and Children's Development: Concepts, Models, and Debates.” See Brady \& Burton 2016:141-65.

Meyer, Bruce D. and Nikolas Mittag. 2019. "Using Linked Survey and Administrative Data to Better Measure Income: Implications for Poverty, Program Effectiveness, and Holes in the Safety Net." American Economic Joumal: Applied Economics 11(2):176-204.

Michener, Jamila. 2018. Fragmented Democracy: Medicaid, Federalism, and Unequal Politics. Cambridge University Press.

Milazzo, Annamaria and Dominique Van de Walle. 2015. Women Left behind? Poverty and Headship in Africa. The World Bank.

Mittag, Nikolas. 2019. "Correcting for Misreporting of Government Benefits.” American Economic Journal: Economic Policy 11(2):142-64.

Working draft_-Please do not cite or quote without author's permission 
Moffitt, R. A. 2008. “Welfare Reform: The US Experience (Working Paper No. 2008: 13).” Uppsala, Sweden: Institute for Labor Market Policy Evaluation.

Mouw, Ted. 2000. "Job Relocation and the Racial Gap in Unemployment in Detroit and Chicago, 1980 to 1990.” American Sociological Review 730-53.

O'Connell, Heather A. 2012. "The Impact of Slavery on Racial Inequality in Poverty in the Contemporary US South.” Social Forces 90(3):713-34.

O'connor, Alice. 2009. Poverty Knowledge: Social Science, Social Policy, and the Poor in Twentieth-Century US History. Vol. 59. Princeton University Press.

Oaxaca, Ronald. 1973. "Male-Female Wage Differentials in Urban Labor Markets.” International Economic Review 693-709.

Pager, Devah. 2003. “The Mark of a Criminal Record.” American Journal of Sociology 108(5):937-75.

Pager, Devah, Bart Bonikowski, and Bruce Western. 2009. "Discrimination in a Low-Wage Labor Market: A Field Experiment.” American Sociological Review 74(5):777-99.

Parker, Kim, Juliana Horowitz, and Brian Mahl. 2016. On Views of Race and Inequality, Blacks and Whites Are Worlds Apart: About Four-in-Ten Blacks Are Doubtful That the US Will Ever Achieve Racial Equality. Pew Research Center.

Parolin, Zachary. 2019a. "Temporary Assistance for Needy Families and the Black-White Child Poverty Gap in the United States." Socio-Economic Review.

Parolin, Zachary. 2019b. "The Effect of Benefit Underreporting on Estimates of Poverty in the United States.” Social Indicators Research 144(2):869-98.

Patterson, Orlando. 2019. "The Denial of Slavery in Contemporary American Sociology." Theory and Society 48(6):903-14.

Patterson, Orlando and Ethan Fosse. 2015. The Cultural Matrix: Understanding Black Youth. Harvard University Press.

Paul, Mark, William Darity, Darrick Hamilton, and Khaing Zaw. 2018. "A Path to Ending Poverty by Way of Ending Unemployment: A Federal Job Guarantee.” RSF: The Russell Sage Foundation Journal of the Social Sciences 4(3):44-63.

Quillian, Lincoln, John J. Lee, and Mariana Oliver. 2020. "Evidence from Field Experiments in Hiring Shows Substantial Additional Racial Discrimination after the Callback." Social Forces.

Quillian, Lincoln, Devah Pager, Ole Hexel, and Arnfinn H. Midtbøen. 2017. "Meta-Analysis of Field Experiments Shows No Change in Racial Discrimination in Hiring over Time." Proceedings of the National Academy of Sciences 114(41):10870-75.

Rainwater, Lee and Timothy M. Smeeding. 2003. Poor Kids in a Rich Country: America's Children in Comparative Perspective. Russell Sage Foundation.

Raley, R. Kelly, Megan M. Sweeney, and Danielle Wondra. 2015. "The Growing Racial and Ethnic Divide in US Marriage Patterns." The Future of Children/Center for the Future of Children, the David and Lucile Packard Foundation 25(2):89.

Working draft—Please do not cite or quote without author's permission 
Rank, Mark Robert. 2004. One Nation, Underprivileged: Why American Poverty Affects Us All. Oxford University Press.

Ray, Victor. 2019. “A Theory of Racialized Organizations.” American Sociological Review 84(1):26-53.

Reskin, Barbara. 2012. “The Race Discrimination System.” Annual Review of Sociology 38:17-35.

Rothwell, David W., Timothy Ottusch, and Jennifer K. Finders. 2019. "Asset Poverty among Children: A Cross-National Study of Poverty Risk." Children and Youth Services Review 96(C):409_ 19.

Sawhill, Isabel V. 2003. “The Behavioral Aspects of Poverty.” Public Interest (153):79-95.

Semega, Jessica L., Melissa A. Kollar, Emily A. Shrider, and John F. Creamer. 2020. Income and Poverty in the United States: 2019. Washington, DC.

Sites, William and Virginia Parks. 2011. "What Do We Really Know about Racial Inequality? Labor Markets, Politics, and the Historical Basis of Black Economic Fortunes.” Politics \& Society 39(1):40-73.

Small, M. L., D. J. Harding, and M. Lamont. 2010. "Reconsidering Culture and Poverty." The ANNALS of the American Academy of Political and Social Science 629(1):6-27.

Smeeding, Timothy. 2016. "Poverty Measurement." The Oxford Handbook of the Social Science of Poverty 1.

Streib, J., S. Verma, W. Welsh, and LM Burton. 2016. "Life, Death and Resurrections: The Culture of Poverty Perspective." Pp. 247-69 in The Oxford Handbook of the Social Science of Poverty, edited by D. Brady and L. Burton. Oxford University Press.

Thiede, Brian C., Matthew Brooks, and Leif Jensen. 2020. “The Contours and Correlates of Child Poverty Across Immigrant Generations.”

Thiede, Brian C. and Matthew M. Brooks. 2018. "Child Poverty across Immigrant Generations in the United States, 1993-2016: Evidence Using the Official and Supplemental Poverty Measures." Demographic Research 39:1065-80.

Thiede, Brian C., Hyojung Kim, and Tim Slack. 2017. "Marriage, Work, and Racial Inequalities in Poverty: Evidence from the United States." Journal of Marriage and Family 79(5):1241-57.

Thiede, Brian C., Daniel T. Lichter, and Scott R. Sanders. 2015. “America’s Working Poor: Conceptualization, Measurement, and New Estimates.” Work and Occupations 42(3):267-312.

Traub, Amy. 2017. The Asset Value of Whiteness: Understanding the Racial Wealth Gap. Demos.

Treiman, Donald J. 2014. Quantitative Data Analysis: Doing Social Research to Test Ideas. John Wiley \& Sons.

Vaisey, Stephen. 2010. “What People Want: Rethinking Poverty, Culture, and Educational Attainment." The Annals of the American Academy of Political and Social Science 629(1):75-101.

Vandecasteele, Leen. 2011. "Life Course Risks or Cumulative Disadvantage? The Structuring Effect of Social Stratification Determinants and Life Course Events on Poverty Transitions in Europe." European Sociological Review 27(2):246-63.

Working draft—Please do not cite or quote without author's permission 
Weller, C. 2019. "African Americans Face Systematic Obstacles to Getting Good Jobs-Center for American Progress." Center for American Progress: Washington, DC, USA.

Williams, Deadric T. 2019. "A Call to Focus on Racial Domination and Oppression: A Response to "racial and Ethnic Inequality in Poverty and Affluence, 1959-2015 "." Population Research and Policy Review 38(5):655-63.

Wilson, William Julius. 1987. The Truly Disadvantaged. Vol. 19.

Wingfield, Adia Harvey and Koji Chavez. 2020. "Getting in, Getting Hired, Getting Sideways Looks: Organizational Hierarchy and Perceptions of Racial Discrimination.” American Sociological Review 85(1):31-57. 


\section{TABLES AND FIGURES}

Table 1. Linear Probability Models of Poverty in the U.S. Households, 1993-2016

\begin{tabular}{|c|c|c|c|}
\hline & \multicolumn{3}{|c|}{$\mathrm{HHs}$} \\
\hline & White & Black & Latino \\
\hline \multirow[t]{2}{*}{ Young Lead... } & $0.143^{* * *}$ & $0.173^{* * *}$ & $0.136^{* * *}$ \\
\hline & $(-0.001)$ & $(-0.002)$ & $(-0.002)$ \\
\hline \multirow[t]{2}{*}{ Single Mother Lead... } & $0.116^{* * *}$ & $0.103^{* * *}$ & $0.068^{* * *}$ \\
\hline & $(-0.001)$ & $(-0.002)$ & $(-0.001)$ \\
\hline \multirow[t]{2}{*}{ Low Educated Lead... } & $0.154 * * *$ & $0.168^{* * *}$ & $0.158^{* * *}$ \\
\hline & $(-0.001)$ & $(-0.002)$ & $(-0.001)$ \\
\hline \multirow[t]{2}{*}{ Unemployed HH... } & $0.318^{* * *}$ & $0.340 * * *$ & $0.287^{* * *}$ \\
\hline & $(-0.001)$ & $(-0.002)$ & $(-0.002)$ \\
\hline \multirow[t]{2}{*}{ Lead $25-34 \ldots$} & $0.024 * * *$ & $0.032 * * *$ & $0.028 * * *$ \\
\hline & $(0.000)$ & $(-0.001)$ & $(-0.001)$ \\
\hline \multirow[t]{2}{*}{ Lead $>54 \ldots$} & $-0.003 * * *$ & $0.004^{*}$ & $-0.004^{*}$ \\
\hline & $(-0.001)$ & $(-0.002)$ & $(-0.002)$ \\
\hline \multirow[t]{2}{*}{ Female lead, no children... } & $0.040^{* * *}$ & $0.010^{* * *}$ & $0.011 * * *$ \\
\hline & $(-0.001)$ & $(-0.002)$ & $(-0.002)$ \\
\hline \multirow[t]{2}{*}{ Male lead, no children... } & $0.015^{* * *}$ & $0.005^{*}$ & $-0.014 * * *$ \\
\hline & $(-0.001)$ & $(-0.002)$ & $(-0.002)$ \\
\hline \multirow[t]{2}{*}{ Number of children... } & $0.016^{* * *}$ & $0.028 * * *$ & $0.030 * * *$ \\
\hline & $(0.000)$ & $(0.000)$ & $(0.000)$ \\
\hline \multirow[t]{2}{*}{ Number $>65$ in HH... } & $-0.049 * * *$ & $-0.067 * * *$ & $-0.058 * * *$ \\
\hline & $(-0.001)$ & $(-0.002)$ & $(-0.001)$ \\
\hline \multirow[t]{2}{*}{ High Educated... } & $-0.055^{* * *}$ & $-0.109 * * *$ & $-0.069 * * *$ \\
\hline & $(0.000)$ & $(-0.002)$ & $(-0.001)$ \\
\hline \multirow[t]{2}{*}{ Multiple-earner HН... } & $-0.095 * * *$ & $-0.197 * * *$ & $-0.234 * * *$ \\
\hline & $(0.000)$ & $(-0.001)$ & $(-0.001)$ \\
\hline R-squared & 0.207 & 0.303 & 0.232 \\
\hline $\mathrm{N}$ & $2,472,745$ & 416,271 & 663,076 \\
\hline
\end{tabular}

Note: Source: CPS-ASEC w/TRIM3 corrections; All models estimated with robust SEs;

SEs in parentheses.

$* \quad \mathrm{p}<0.05$

** $\quad \mathrm{p}<0.01$

$* * * \mathrm{p}<0.001$

Working draft—Please do not cite or quote without author's permission 


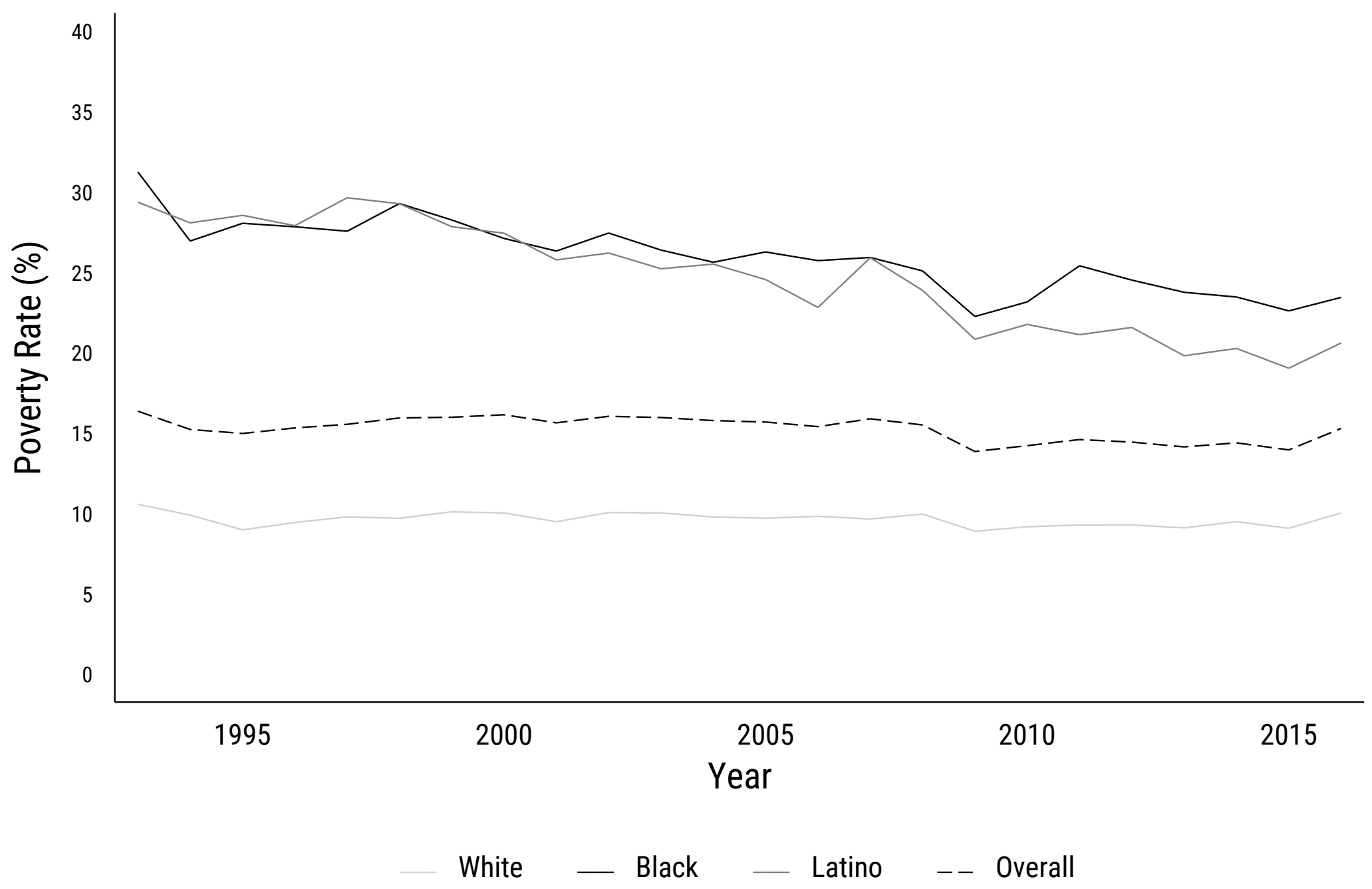

Figure 1. Trends in Poverty Rates by Race/Ethnicity, 1993-2016 using CPS-ASEC with TRIM3 corrections. Poverty is defined as equivalized $\mathrm{HH}$ income less than $50 \%$ of national median. 
(A) Low-Educated Leads

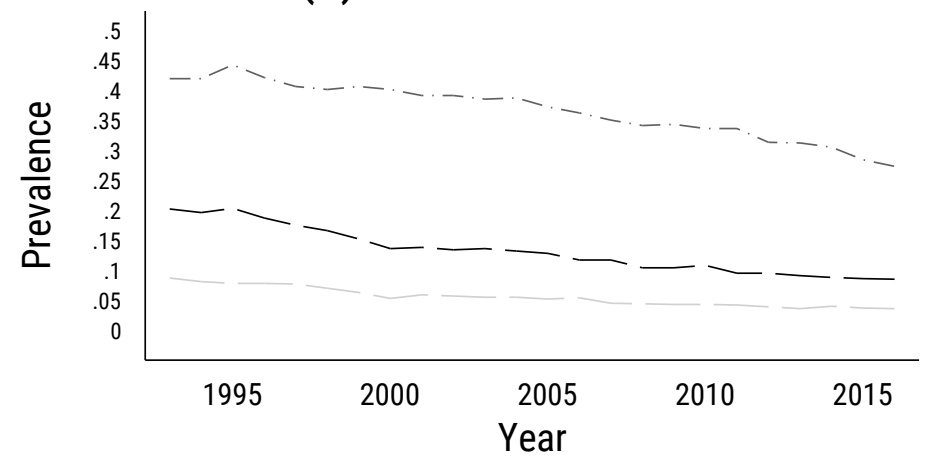

(C) Unemployed Households

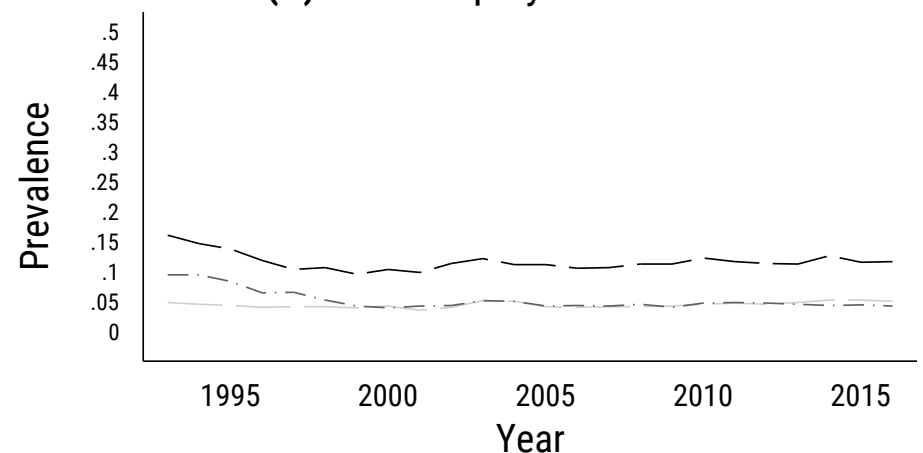

(B) Single Mother Leads

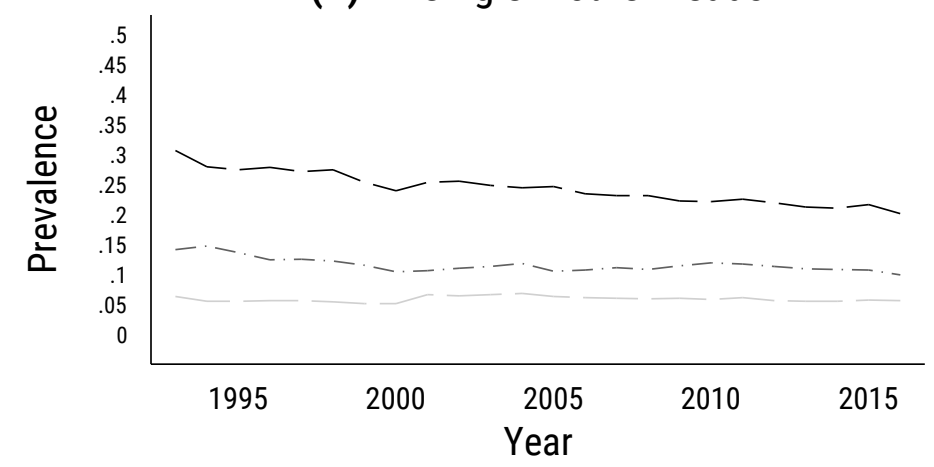

(D) Young Lead (Under 25)

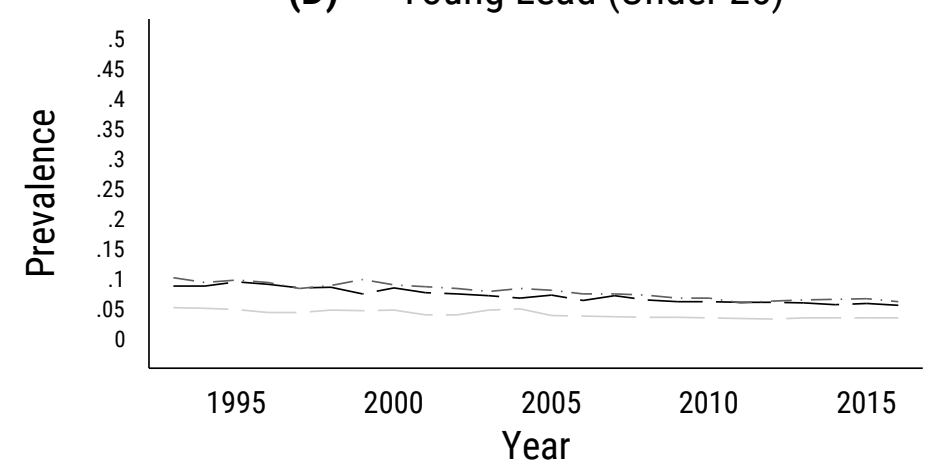


(A) Young Lead

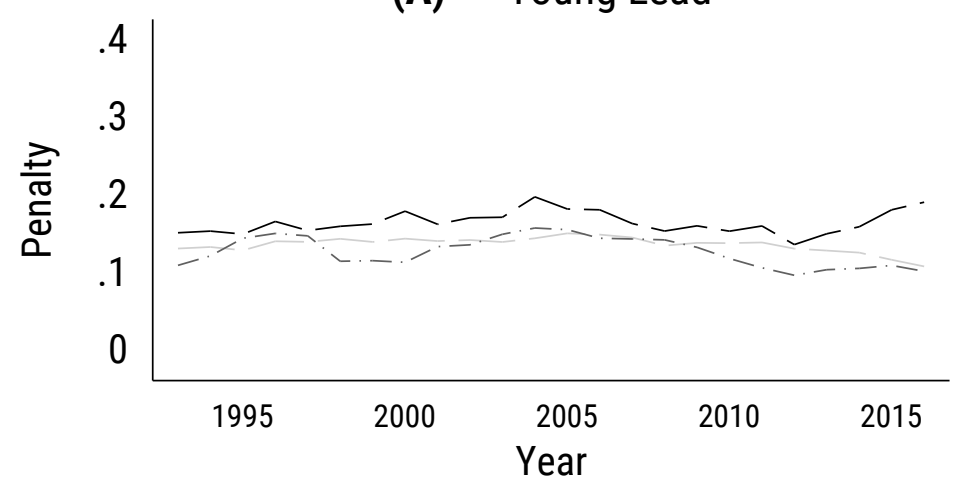

(C) Low Education

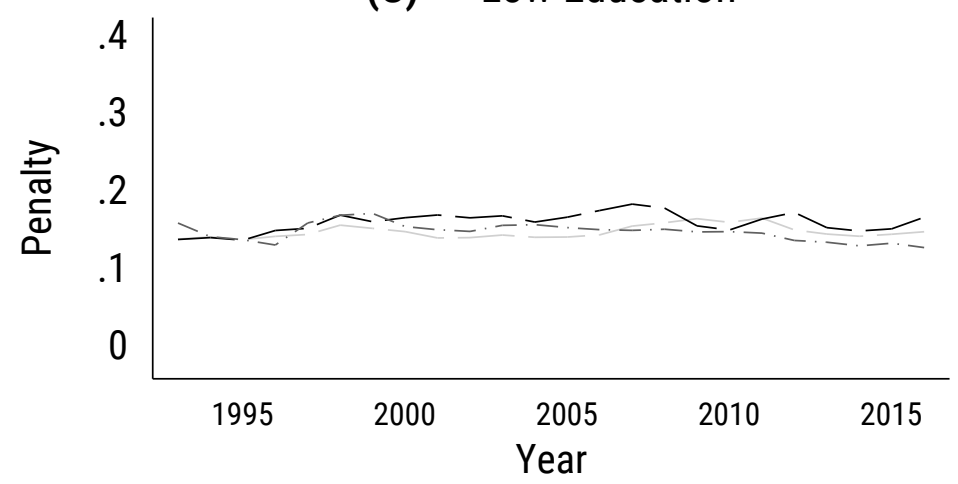

(B) Single Mother

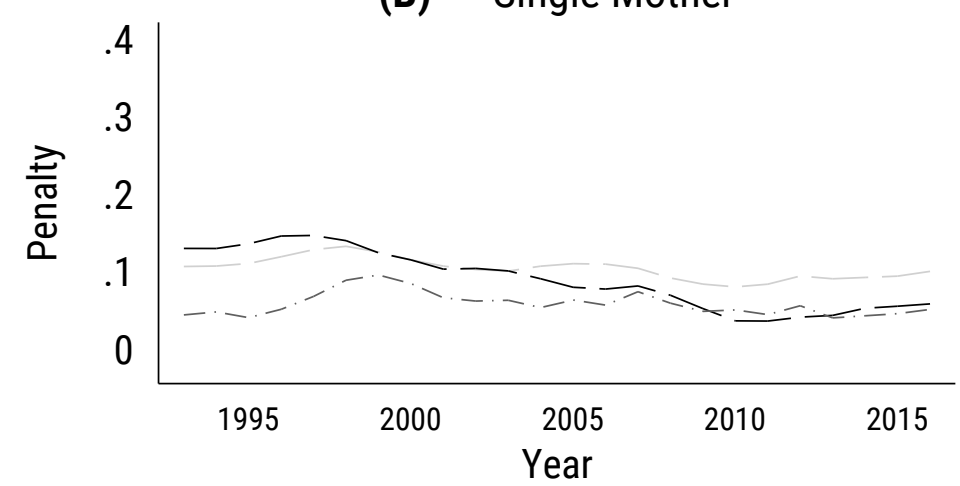

(D) Unemployed $\mathrm{HH}$

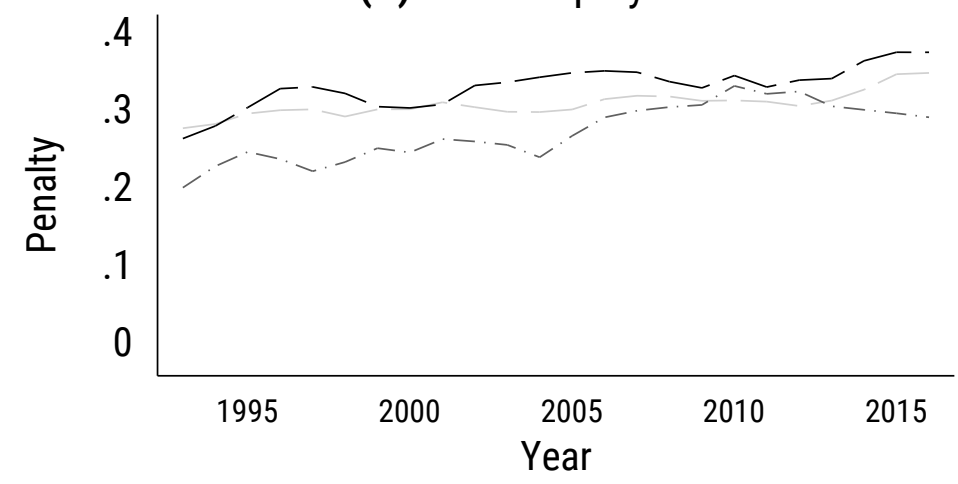

White _ Black _.- Latino

Figure 3. Penalties associated with the four primary risk factors by ethno-racial group; 1993 to 2016 


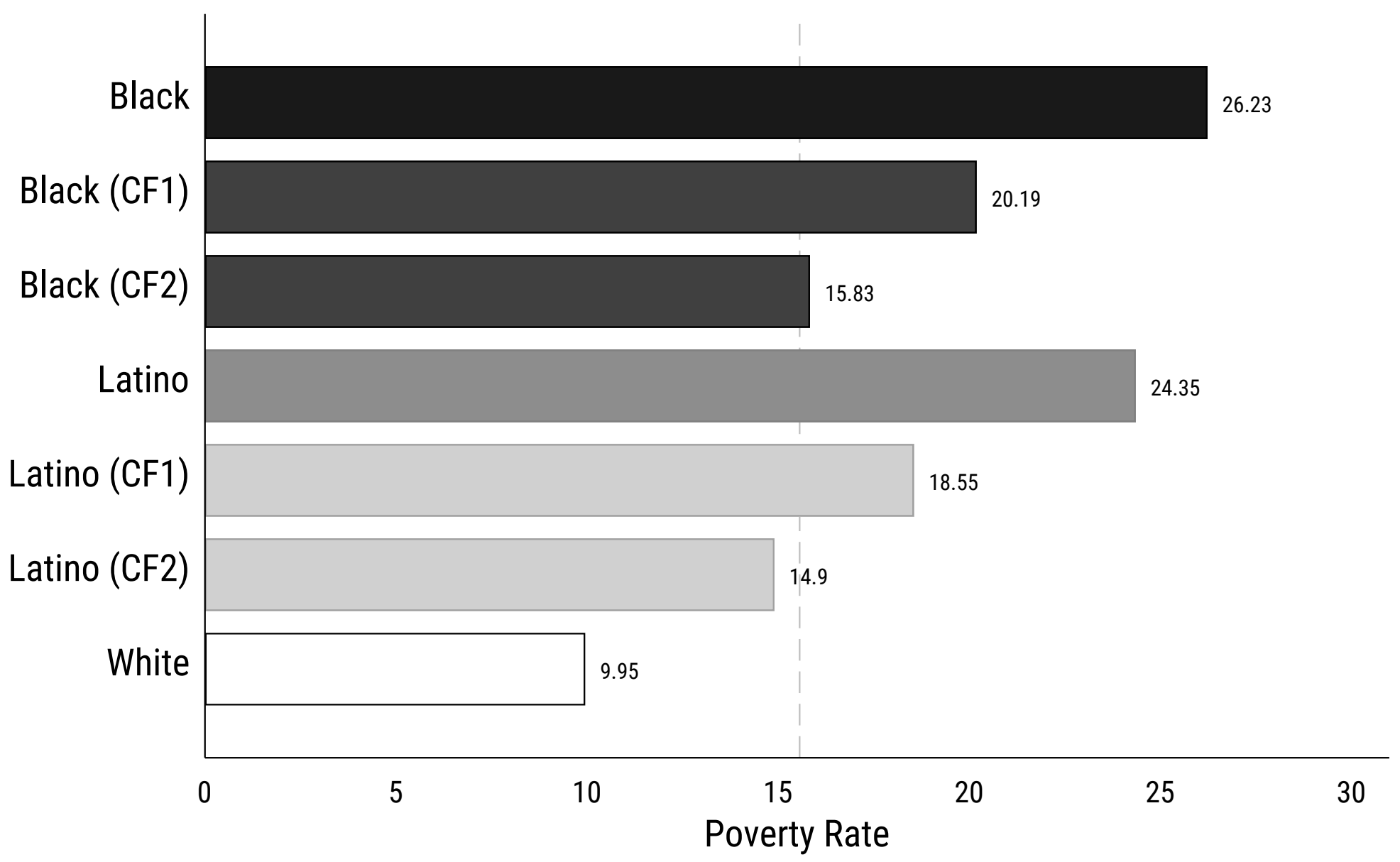

Figure 4. Predicted poverty rates by ethno-racial group compared to counterfactual estimates. CF1 is poverty predicted using white prevalence of risks in Black and Latino individuals CF2 is poverty predicted using zero prevalence of risks in Black and Latino individuals Dashed line represents average overall poverty rate. 